\title{
Training of professional and personal development of a manager as a multifunctional psychological practice
}

\author{
Alexandra Kriulina ${ }^{1, *}$ \\ ${ }^{1}$ Kursk State University, Kursk 305000, Russia
}

\begin{abstract}
Training of professional and personal development of a Manager is analyzed as a multifunctional psychological practice. A brief history of changing the status of training in Russia and the attitude of scientists to it is presented. Practical, theoretical and methodological substantiation of the author's point of view on training as a special kind of psychological practice is given. The main functions of the training are described in detail: psychotherapeutic, motivational, developmental, diagnostic, learning. The functions are described using examples from the specific practice of conducting training with adult business school students who have the status of a Manager in their professional field. An original form of determining the quality of managers ' training using training is proposed: development and description of a personal program of personal and professional development for the next two years. The perspective of training research as a psychological practice is outlined.
\end{abstract}

\section{Introduction}

In the classical psychological understanding, training is usually considered along with such active learning methods (AMO) as business and role-playing games, the case method and the incident method, group discussion, and the immersion method [1]. At the same time, training occupies a special place in this series, since an experienced trainer can use all the listed active methods in the course of training sessions, which greatly enhances its effectiveness.

At the end of the 20th century in our country, training was treated with distrust. Representatives of academic psychology and supporters of the natural science paradigm of psychological research unjustifiably considered it as "acting", and the labor-intensive and energy-intensive work of a coach as the work of a mass entertainer. With the advent of the new century, the situation has changed dramatically: special training programs for trainers have been developed, the number of types of training work has increased, video training programs have appeared, and in some universities, training has replaced traditional seminars and practical classes. Finally, the trainings became the subject of interested discussion at scientific conferences and served as the basis for discussions during the defense of $\mathrm{PhD}$ and doctoral theses in psychology.

* Corresponding author: anitim@list.ru 
In Russia, the boom in interest in AMO occurred in the last decade of the last century and continues in the new century [2]. Business games and organizational and business games become the focus of interest [3]. Against this background, the attempts of individual psychologists to master training as an effective, in their opinion, means of educating adults looked very modest. As a result, the training still received recognition and wide application in the practice of training. In the West, the palm tree in organizing the first training groups belongs to K. Levin. It happened back in 1946. In Russia, L. A. Petrovskaya is deservedly considered a recognized leader in the organization, improvement and dissemination of social and psychological training. All her works on training problems were collected by her colleagues in the Department of social psychology of the Moscow state University and published after her death [4].

Back in 1984, during an internship at the faculty of psychology of Moscow state University, the author of this article was lucky enough to meet Larisa Andreevna not only through her publications, but also in collaboration. As a teacher, she introduced the course participants to the elements of training work and aroused great interest in the training. Personally, I have retained this interest for decades, and it has been translated into training in the specialty "psychological training of a manager"with the qualification of a teacher in psychological training. From the mouth of Larisa Andreyevna, we learned about the types of training conducted by Western psychologists. Publications on this topic were then in the manuscript stage. When they were published, we fully appreciated the scientific generosity of our teacher. As the scientific supervisor of my final work on the topic "Group discussion", L. A. Petrovskaya showed me an example of an interested and at the same time caring attitude towards a novice researcher. Her friendly communication with me served as a good example in future work with young scientists. We managed to convey the interest in the training to our students: out of nine people who received a PhD in psychology, four of them used training or its elements in their scientific work.

This study is devoted to the substantiation of a fundamentally new status of training. The author of the article with thirty years of training experience has practical reasons to consider training a full-fledged psychological practice. However, this statement, which is based only on practice, needs to be further argued, referring to reliable scientific sources of methodological and conceptual plan. And if the title of the article looks more like a hypothesis before justification, then after scientific analysis to find strong arguments in its favor, the same title will acquire the status of a scientific statement. It is advisable to divide the upcoming analytical work into two interrelated and complementary tasks. The first task of the study is to substantiate the statement about the new status of the training. The second task is aimed at identifying the main functions of training, which is understood as a type of psychological practice.

Let's define the relevance of the chosen research problem. In the scientific literature on the problems of training there are several types of disparities. The predominance of theoretical works over practical and practice-oriented ones. The predominance of works describing trainings with schoolchildren and students over the presentation of the features of training with adults. The predominance of field trainings organized with the staff and managers of organizations that act as a social customer, compared to the number of trainings attended by employees of different enterprises. This study is intended to fill in the lack of scientific information on problems and ways to solve them in training groups formed according to the last of these options.

\section{Methodology}

We believe that the initial strong arguments for the upcoming analysis are the features that the author of the theory of understanding psychotherapy F. E. Vasilyuk called aspects and 
introduced them to distinguish between academic (natural science) and psychotechnical (oriented to psychological practice) cognition [5].

In the retrospective analysis, we also used methodological, theoretical and conceptual developments of other domestic and foreign psychologists. Let's name the most significant of them. These are the differences between idiographic and nomotetic approaches to research in psychology. We should mention the positive psychology of R. Emmons on the meaning of life and human growth through suffering (2004), and the positive psychotherapy of $\mathrm{N}$. Pezeshkian (1992), the concept of living knowledge and the vertical development of V. P. Zinchenko (1998), the concept of mental regulators of E. A. Klimov (1988), on the integrative resource of psychotherapy of V. L. Savelichevoy (2019).

\section{Main results of the research}

The subject of the retrospective analysis is the training of professional and personal development of the Manager. This training was developed by the author of the article, it was included in the training program for managers and used for the last 10 years at the Kursk regional business school. During this time, ten generations of students have been trained under the program. As a rule, these are people who have received pedagogical, medical, technical and agricultural education, and who hold managerial positions at various levels in their field of activity. Most of them realized the need to get an economic education in the field of management.

In the previous 20 years, before the start of the training at the business school, we pursued the development and improvement of another training. It was called "Social and psychological communication training". It was used not only in working with schoolchildren and students, but also with managers at various levels in the field of education and industrial enterprises. That is why many of the tools of this training formed the basis for the development of a new program called "Training for professional and personal development of a Manager".

Starting with the scientific analysis, we note that two interrelated and interdependent tasks will be solved, which have relative autonomy. That is why it is advisable to solve them consistently. The solution of the first problem is aimed at substantiating the claim that the analyzed specific training is a kind of psychological practice. The solution of the second problem is focused on proving the polyfunctionality of this practice.

We will show that the characteristic features of psychotechnical cognition, identified by F. E. Vasilyuk and growing, in his opinion, from psychological practice, are fully inherent in training. Further enumeration of them will be accompanied by a description of the specific manifestation of each trait in the training process.

1. Reliance on the "philosophy of practice" rather than on epistemology. Most of the time spent on training sessions is used for role-playing games, psychotechnical games and exercises, drawing techniques, meaningful analysis of parables and solving logical problems. Students get acquainted with the theory in a dosed manner, when there is a need to comment on the results of practical tasks performed by students.

2. The Subject of knowledge is not a separate person, but a "total subject" of knowledge (Vasilyuk, 1992). The joint process of cognition and mutual recognition includes as much as possible all participants of the training and the coach himself, who occupy an interested, rather than a detached position, as a researcher in a classic psychological experiment.

3. The research process and procedures are flexible in contrast to the" rigid " experimental programs of academic knowledge. Of course, the training program is developed in advance. However, it is adjusted to meet the wishes of each new generation of business school students. In the first lesson, an anonymous written survey of the audience's expectations is conducted. Then the expectations are carefully analyzed by the trainer in order to identify 
specific wishes and take them into account in the correction process when planning every next day of classes.

4. Contact - in natural science research, contact with the subject is considered as a factor that distorts the objectivity of the received data. Emotional contact of the trainer with the group members is a necessary condition for full and lively communication with them throughout the training.

5. The training is carried out with the consciousness of the audience, and not its experimental research on certain parameters. The training ends with a test, which takes place not in the traditional form of a question-answer, but through the independent development of each student's personal (professional and personal) development program. Check programs and written anonymous feedback at the end of the lessons show how well students have perceived, understood and implemented in the program received during the training, a fundamentally new information: about themselves, about others, about the coach, about the training process. Without reflection, writing a high-quality program is very difficult.

So, the comparative analysis is complete. It allows us to draw two important conclusions: first, the analyzed training, without any doubt, is a real psychological practice, its special kind. Secondly, since training has the main features of psychotechnical cognition based on understanding psychotherapy, it can be argued that it has a psychotherapeutic function. The psychotherapeutic effect of the training is also evidenced by the statements of the audience at the end of each meeting. Business school classes are held on-the-job. What is the surprise of listeners when they after having worked in their organization full-time and then after having completed another lesson in the form of training, they feel the desire to continue working. It turns out everything is in accordance with the theory of I. P. Pavlova: the best rest is a change of classes. From the accumulated fatigue of the day or minor manifestations of tension, noticeable at the beginning of the meeting, there is no trace of its end.

The very title of the article recods the fact that training as a psychological practice is a multifunctional phenomenon. Therefore, the immediate task is to identify other training functions and illustrate them with examples from the long-term practice of the author of the article on training.

In our opinion, the next most important thing is the motivational function, as an important source of activity for students during all meetings with the coach. This function is provided by the skill of the coach at the first meeting and is further supported by certain techniques at all subsequent meetings. An anonymous written survey of listeners ' expectations has a great motivational potential. In their notes, they list their concerns. These problems concern both professional and family-personal spheres. Sometimes directly, and more often indirectly, participants of the training express their hope for the coach's help in finding ways to solve these problems. Awareness of problems and expectation of their resolution are sources of increased interest in meetings, and, consequently, cognitive motivation of a sufficiently high level and personally significant for listeners.

An additional source of motivation is information about the vectors of professional and personal development. The vectors of professional development include three aspects of business communication: perceptual, communicative and interactive. The types of selfdetermination according to E. Erickson (1996) are chosen as vectors of personal development: physical, intellectual, social, professional, and moral self-determination. The importance of information about development vectors is determined by the need to use it at the end of the training to develop a personal development program for the next two years.

The developing function is the second most important after the motivating one. It is important to emphasize that the training process simultaneously develops both the participants and the coach, provided that they are fully and actively involved in the work process. The research of previous years, reflected in earlier publications of the author of the article $[6,7]$. is devoted to a detailed analysis of the training potential for the development of 
all its participants and the development of instrumental development tools. There is an additional source of information about the development results of business school students in the training process - feedback.

The feedback in the last session also reveals the discoveries made by the students about themselves and others. Some of them found that it is possible to communicate normally even with unpleasant people, you can persuade them to your point of view, without offending. Others have discovered the need to improve certain character traits that increase communication effectiveness. Still others realized that the friendly atmosphere in the group gave them confidence to communicate with strangers. They also discovered the friendly communication style of the coach and his ability to address all members of the group with a smile. It is also important to discover that communication is a very serious process that needs to be prepared carefully and for a long time.

The diagnostic function is not shown in all participants of the training and to varying degrees. In psychological literature, there is a metaphor that people are living "mirrors" in which you can see your reflection. Everyone has the opportunity, but not everyone can see it. Other members of the group are one source of diagnostic information about themselves. The second source is video recordings that are appropriate to use during the training. They contain images of training participants that you can work with for a long time, repeatedly referring to the video. During repeated viewings, a particular person notices new and new features in their appearance, behavior, and relationships with partners in the video. This increases the amount of diagnostic information about your person. The third source of diagnostic information is the results of all practical tasks offered by the trainer. They contain additional "touches" to the image of the person of each business school student, which will be useful in developing a personal development program.

The learning function. It is inherent in training as a type of AMO. In today's rapidly changing, and therefore unpredictable life, there are challenges addressed to domestic education, both in higher education and in postgraduate training. One of these challenges is the competence approach, according to which educational standards and the list of competencies to be formed are updated every 5 years. A notable phenomenon was the appearance of the FSES 3++, which contains universal competencies. These are the competencies that graduates of different faculties should have by the end of their studies.

It is useful for business school students to know universal competencies for two reasons. First, as employers, for the correct selection and subsequent certification of the staff of their organizations. Secondly, as modern professionals who must have universal competencies to meet the challenges of the time. Therefore, at one of the training sessions, students are introduced to a full set of universal competencies for Russian universities. In our opinion, it is advisable to supplement them with the competencies formulated at the world economic forum.

This work of the coach with the group does not pass without a trace for its participants. This is easy to see when checking personal professional and personal development programs for the next two years. By and large, the development of these programs as a test task is the embodiment of the results of self-design. The rationale for this possibility and the description of self-design tools are presented in an earlier publication of the author of the article [7].

It should be noted that not all programs, but quite a large number of them contain such universal competence as system and critical thinking. Students of the business school in the description of the program provide tools for the development and control of this competence. This means their conscious choice, which they plan to implement in the process of selfdevelopment for the next two years. This selection also reflects the results of a comparative analysis of the lists of universal competencies from the standard and those proposed by the world economic forum for 2020. Of the ten competencies in this list, exactly half are included in the same semantic field with the competence "system and critical thinking": solving 
complex problems, analytical thinking, creativity, emotional intelligence, and flexibility of thinking. It is possible that this circumstance is the basis for the preference of systematic and critical thinking as a vector of development for the next two years.

\section{Discussion}

The main results of the study can be attributed to new ones, if we consider them in the context of the content of the concepts "external" and"internal". Traditionally, the training of managers in different disciplines discusses the problems of the external environment of the organization and its internal environment. However, there is a different interpretation of the concept of "internal environment", first identified by a Russian psychologist in the introductory article to the book"Psychology of the living environment". He understood it as a microcosm enclosed in the human body [8]. Foreign scientists realized the importance of the internal environment of the employee only after thirteen years [9]. Both domestic and foreign works deal with the internal environment of each participant in the workflow.

It is appropriate to extrapolate the concept of the internal environment in the designated sense to the structure of the educational space. In the conditions of training, the trainer's attention is focused on the internal environment of the educational space and on the changes taking place in it. It should be added that each of the five functions of training as a type of psychological practice is focused on transforming the inner world of business school students. The internal environment is part of the structure of the internal environment of the organization, the components of which are other environments: social environment, information environment, artificial working environment [10].

In our opinion, in future work with students of the business school, it is advisable to continue studying the training opportunities, based on the well-known idea Of L. S. Vygotsky that training leads to development. As his students and followers rightly believe, this idea, which has been repeatedly proven by experience and practice, should be applied consciously and with caution in the use of the accompanying concepts of "zone of immediate development" and "actual development" [11].

The problem of the role of reflexive processes in self-design is interesting and promising for research. The following two works can be useful in this regard. One of them experimentally proved the role of reflexive analysis in adult decision-making about the need for life changes. The reason for this conclusion was the established fact of increased reflection at the beginning of age-related crises of adulthood [12]. In the second paper, a classification scheme for types of reflection is proposed, of which preference is given to a detailed description of the praxological type as a fundamentally new one that provides solutions to professional and everyday practical problems [13].

The three types of reflection that the author of the second work included in the classification (intellectual, personal and reflection as a dialogue) in an earlier publication were considered as a harmonious Trinity of personal, intellectual and communicative reflections. Being balanced and coordinated, they provide rational resolution of critical situations by the subject of professional activity [14].

\section{Conclusions}

1. The reasoned recognition of training as a kind of psychological practice significantly increases its social significance in the training of qualified managers. Social significance is integrated in the content of the five main functions of such practice: psychotherapeutic, motivational, developmental, diagnostic, and educational. 
2. The effectiveness of the implementation of the main functions of the training largely depends on the involvement of all its participants in the process. This condition applies to both the coach and students of the business school, its participants.

3. Promising areas of study of training as a psychological practice are the study of two problems that meet the challenges of the time: the identification of training opportunities in relation to universal competencies, the study of the influence of reflexive qualities of training participants on the process of self-design, including predicting the behavior of a Manager in critical situations.

\section{References}

1. R.M. Granovskaya, Elements of practical psychology (Speech, SPb, 2007)

2. V.V. Chechet, Active methods of teaching in pedagogical education (BSU, Minsk, 2015)

3. A.P. Panfilova, Bulletin of the Baltic pedagogical Academy. Intensive methods and technologies in training and professional development of the individual: opportunities, prospects, problems of risk 72, 13-32 (2006)

4. L.A. Petrovskaya, Communication-competence-training: selected works (Smysl, M., 2006)

5. F.E. Vasilyuk, Moscow psychotherapeutic journal 1, 15-32(1992)

6. A.A. Kriulina, Materials of the IV International scientific and practical conference "Innovative potential of subjects of the educational space in the conditions of modernization of education" (Rostov-on-Don, 2013)

7. A.A. Kriulina, Collection of materials of the annual Congress "Psychology of the XXI century: New opportunities" (YarSU, MAPN, Yaroslavl, 2016)

8. L.A. Kitaev-Smyk, Psychology of the life environment (Mysl, Moscow, 1989)

9. H.W. Hendrick, B.M. Kleiner, Macroergonomics: Theory, methods, and applications (Lawrence Erlbaum Associates, Mahwah, New Jersey, 2002)

10. E.A. Klimov, Ways to professionalism. Psychological view (Mosk. psychological and social. in-t: Flint (sue IPK Ulyan. Print house), Moscow, 2003)

11. G.G. Kravtsov, E.E. Kravtsova, Cultural and historical psychology 1(16), 4-12 (2020) DOI: https://doi.org/10.17759/chp. 2020160101

12. M.V. Klementieva, Cultural and historical psychology 1(12), 14-23 (2016) doi: 10.17759/chp. 2016120102

13. V.K. Vasilev, Cultural and historical psychology 3(12), 208-225 (2016) doi: 10.17759/chp. 2016120311

14. F.E.Ivanov, V.V. Smolyaninov, E.M. Filippova Reflexive processes and management 2(3), 70-83 (2003) 